\title{
La crónica-historieta en Macanudo, de Liniers
}

\section{Queiroz, Jozefh}

Resumen:

Desde el año 2002 en el diario La Nación, se publica la serie Macanudo, de Ricardo Siri Liniers. Caracterizada por su humor nonsense, sus personajes pertenecen a distintos universos, como los pingüinos, Enriqueta y su gato Fellini, las aceitunas, la Vaca Cinéfila, el Misterioso Hombre de Negro o el propio autor representado como un conejo. Tras más de una década de publicación, la serie tiene ya casi 4 mil tiras publicadas, prácticamente en un ritmo diario. Analizar la complejidad de este autor demanda un amplio aparato teórico: aspectos metalingüísticos, la subversión de la forma de narrar en el formato cómic y también el juego con otras formas de lenguaje, como el cine e internet, son algunos elementos

Cuadernos del Centro de Estudios de Diseño y Comunicación №74

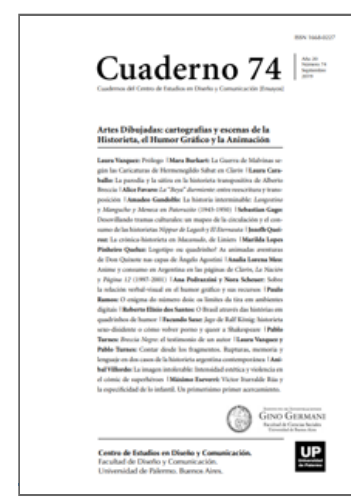

ISSN: 1668-0227

Artes Dibujadas:

cartografías y

escenas de la

Historieta, el Humor

Gráfico y la

Animación

Aires, Argentina | 256 páginas

Año XX, Septiembre 2019, Buenos

descargar PDF

ver índice de la publicación

Ver todos los libros de la publicación

compartir en Facebook

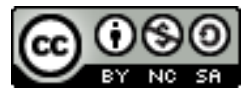

Esta obra está bajo una Licencia Creative Commons Atribución-NoComercialCompartirlgual 4.0 Internacional característicos de su obra. En este estudio, se propone lanzar una mirada atenta a las formas en las que el autor se expresa ante los hechos que ocurren en la sociedad argentina y en el extranjero, simulando el género crónica, comúnmente vehiculado por los periodistas de los principales medios de comunicación. De esta manera, se propone observar la relación intertextual entre la historieta y la crónica, enfatizando sus puntos de intersección y la influencia de uno sobre el otro. Además, se observa el modo en que el autor utiliza el espacio de la tira para presentar su mirada crítica ante los hechos relevantes del mundo.

Palabras clave: Macanudo - Liniers - Crónica - Historieta - Intertextualidad.

$\left(^{*}\right)$ Profesor en la Universidad Federal de Alagoas, en Brasil, donde ejerce la docencia de la lengua española y enseñanza de idiomas, además de realizar investigaciones sobre la historieta. 
Pensar la sociedad argentina, especialmente si nos encontramos en otro país como Brasil, donde las informaciones que circulan son bastante genéricas, demanda una mirada más crítica y personal; así que reflexionar sobre algunos eventos se nos hace más difícil. Esto nos mantiene distantes aunque tengamos muchas características similares, especialmente en el aspecto político y económico.

Liniers, que lleva más de una década publicando sus historietas en el diario La Nación, empezó a ser publicado en Brasil recién en el año 2008. La publicación del autor es batante reciente, por lo tanto demandará tiempo hasta que el público brasilero conozca su versatilidad, que lo traslada continuamente desde el humor nonsense a la crítica política sin abandonar su mirada cómica.

En lugar de la fantasía frecuentemente explorada por Liniers, este breve estudio plantea analizar cómo el lenguaje de los cómics y el mundo real del lector dialogan en la composición de la narrativa gráfica. Las historietas se convierten en registro de los acontecimientos urbanos y evidencian una conexión con la crónica. En este proceso, se destaca la memoria de la ciudad como eje de las dos formas narrativas. Se habla de una imagen fundamentalmente intertextual de la ciudad, dado que el espacio urbano representado por Liniers permite que los dos géneros dialoguen con los eventos que suceden en la vida del lector/ autor. Steimberg ya remotaba esta característica abierta del cómic al mencionar que "sin referente no hay chiste posible" (2013, p. 164).

Se trata de un autor signado por una característica intertextualidad e intermedialidad, en continuo contacto con otros campos del arte, como la literatura, el cine, internet y la música, entre otras áreas. Liniers utiliza el lenguaje de la historieta para abordar la ciudad desde un punto de vista documental, transformándola en el escenario del registro de las acciones que tienen lugar en el espacio urbano, ampliando su capacidad narrativa, puesto que amplía las estrategias utilizadas para elaborarla. De acuerdo con Ludmer (2013), este proceso inaugura nuevas formas de narrar; es un movimiento natural, originario de la aglutinación de dos o más características distintas, por ejemplo, la reunión de aspectos del cómic y de la crónica periodística:

Supongamos que el mundo haya cambiado y que estamos en otra etapa de la nación, otra configuración del capitalismo y otra era en la historia de los imperios. Para poder entender este nuevo mundo (y escribirlo como testimonio, documental, memoria y ficción), necesitamos un aparato diferente de aquel que anteriormente usábamos. Otras palabras y conceptos, porque no solamente el mundo ha cambiado, sino que también los modelos, géneros y especies en los cuales acostumbrábamos a dividirlo y diferenciarlo. (Ludmer, 2013, p. 7)

En su reflexión, Ludmer nos invita a imaginar el mundo como tiempo. En el espacio urbano, sus transformaciones, relaciones y movimientos dinámicos requieren otras formas de registro y narración, anteriormente desconocidos o simplemente inexplorados. Frente a otros géneros narrativos, la historieta es la que decide descubrir nuevas formas de contarse e inaugurar mecanismos de narración, como se ve en la obra de Liniers. Si hay cada vez más pluralidad en las relaciones humanas y en los sentimientos existentes en el espacio urbano, las herramientas actuales de registro de esos elementos podrían ser insuficientes para comprender y narrar toda la complejidad de nuestras relaciones.

De esta forma, las historietas gradualmente pasan a aglutinar características de otros géneros narrativos. En nuestro caso, veremos cómo incorpora la crónica, simulando sus efectos y ampliando el potencial discursivo del cómic. A través del análisis de algunos registros del autor, será posible notar que en este proceso no hay 
necesariamente una pérdida de su capacidad imaginativa ni de los elementos que componen su aspecto cómico, como puede verse en la sátira. (Ver Figura 1)

La tira presenta elementos fantásticos que son inherentes al humor peculiar de Liniers, como la presencia de animales realizando acciones humanas y reflexionando sobre su lugar en la sociedad, mientras piensan en ejecutar su venganza contra los humanos. Por la lectura de los diálogos, se observa que el autor convoca un repertorio de experiencias previas del lector, convirtiéndolo en la figura fundamental para atribuir sentido a la narrativa. El humor solo se desencadena cuando se entiende la referencia al virus Influenza A H1N1, que fue popularmente conocido como "gripe porcina" o "gripe del cerdo" en el momento de su pandemia, registrada en 2009. Argentina fue uno de los lugares con mayor número de casos, junto a países como México, Estados Unidos y Canadá. El pánico creado por el miedo a contraer el virus, evidenciado por el abordaje masivo en medios de comunicación, fue registrado en la historieta.

Liniers articula una de sus herramientas narrativas más frecuentes: la presencia de animales que actúan como seres personificados, a dos elementos pertenecientes a la realidad del público: el estado de pánico en el cual las personas se encontraban en el momento de la pandemia y la imagen originaria del término "gripe porcina", responsabilizando a los animales que protagonizan la tira. Lo que anteriormente sería simplemente una sátira có- mica, adquiere un sentido propio, al pasar al diálogo con el cotidiano del lector, que exige el repertorio de experiencias necesarias para comprender la situación representada. Consecuentemente, será posible comprender la desesperación de los humanos que figuran en la sátira. Los lectores que no se hallaran familiarizados con el caso, especialmente aquellos que estén en otros países, por ejemplo, posiblemente no comprenderán la característica de crónica que la historieta asume, es decir, el referente del cual habla Steimberg.

Situación semejante ocurre en la siguiente tira (Ver Figura 2), que también se realiza a partir de la articulación de elementos externos a la narrativa gráfica con elementos intrínsecos del cotidiano del lector.

Publicada el 6 de agosto de 2014, la sátira presenta un sutil homenaje a Estela de Carlotto, líder de Abuelas de Plaza de Mayo, el conocido grupo de mujeres argentinas activistas que buscan a sus hijos y nietos desaparecidos en el periodo de la dictadura militar argentina, ocurrido entre los años 1966 y 1973 . Sobre el contexto de la tira, el día anterior a su publicación había sido encontrado el nieto de la líder del grupo, Guido, después de 35 años de intensas búsquedas y fuerte activismo por parte de Estela de Carlotto. El acontecimiento generó una gran conmoción pública en toda Argentina, considerándose el reconocimiento y la importancia que tiene Carlotto como activista1 .

Con este gesto, el historietista abdica temporariamente su rutinario humor para que su arte asuma el carácter de crónica urbana, mostrando, en sintonía con las noticias, su empatía con el caso. Sin adoptar un tono sensacionalista y evitando tocar las heridas todavía no cicatrizadas provocadas por la sanguinaria dictadura, en un gesto metonímico, el autor resalta la importancia de la militancia liderada por Carlotto, representando en su narrativa gráfica uno de los resultados producidos por su arduo trabajo que lleva ya varias décadas. En la sátira, notamos que no se mencionan los nombres de los personajes relacionados al caso, como si se tratase no solamente de un homenaje al caso en cuestión, sino una señal de esperanza para las demás madres y abuelas que siguen buscando a sus seres queridos desaparecidos, como puede verse en la ausencia de rostros específicos que referencian a Carlotto y a su nieto. 
Al mencionar esta forma sutil en que la crónica aborda temas de gran seriedad, el crítico literario brasileño Cándido afirma que "esta [la crónica] se ajusta a la sensibilidad de todos los días. Principalmente porque elabora un lenguaje que habla acerca de nuestro modo de ser más natural. En su ausencia de pretensión, humaniza" (1980, p. 13).

Este recurso narrativo de Liniers ha sido explorado con énfasis en los años más recientes de su producción. A principios de 2015, otros dos casos significativos - uno nacional y otro extranjero- llamaron la atención del autor, que inmediatamente se manifestó por medio de su arte, siendo representados como crónicas en el formato de historieta. El primero de los eventos denuncia sutilmente ciertas acciones del gobierno argentino, en aquel momento presidido por Cristina Kirchner, ante una grave crisis política que enfrentaba y que llegó a consecuencias trágicas. Liniers rescata su posición ante el caso en la siguiente sátira (Ver Figura 3).

El humor existente en la tira se origina de la conclusión de que los fantasmas que atormentan a los niños ya no son las figuras pertenecientes al imaginario infantil, sino los elementos que están presentes en su cotidiano político, como la mención a un órgano investigativo del gobierno. La referencia a la Secretaría de Inteligencia denuncia la investigación inconclusa del asesinato del fiscal argentino Alberto Nisman, encontrado muerto en su residencia el 19 de enero de 2015. Nisman había denunciado a la presidenta por encubrir Irán en actos terroristas ocurridos en 1994 a la Embajada Judía a cambio de favores políticos.

Realizadas las primeras investigaciones oficiales, la Secretaría de Inteligencia presentó insatisfactorias conclusiones a la población, afirmando que el fiscal había cometido suicidio, aun habiendo varias pruebas en contrario. En esta narrativa, el autor utiliza la repercusión del caso y lo incorpora a su repertorio humorístico, nivelando aquellos que componen dicha secretaría al plano de otras criaturas temerosas. Así manifiesta su desconfianza referente a las declaraciones del Gobierno, una vez que se sospechaba que había la pretensión de asesinarlo para encubrir el crimen que el fiscal investigaba. Además, otro aspecto característico del humor de Liniers, sin olvidar la seriedad del caso, es que incluso los niños pasaron a desconfiar de las figuras gubernamentales, dado que el caso no ha llegado a conclusiones satisfactorias. La ironía de la sátira consiste en el hecho de que hasta para los niños el caso produjo resultados misteriosos, generando temor y duda, satirizando la forma como el gobierno supuestamente ha subestimado la población respecto a las respuestas sobre el caso.

El otro caso corresponde al 2015, que resultó en gran proyección internacional. Fue el atentado terrorista ocurrido en París el 7 de enero en la sede del periódico humorístico Charlie Hebdo, que anteriormente había publicado una caricatura del profeta Mahoma, lo que provocó la furia de los grupos extremistas religiosos. En esta ocasión, por lo menos 23 personas fueron víctimas del atentado, contabilizando 12 muertos2 . Miles de personas en el mundo se solidarizaron con el caso y expresaron su duelo en las principales redes sociales. El apoyo a los integrantes del periódico se reprodujo con la frase Je suis Charlie, que se convirtió en eslogan reivindicatorio por la libertad de expresión y contra el terrorismo. Sin embargo, el autor utiliza este contexto y conocimiento del lector para elaborar su historieta-crónica para recordar otro evento posterior, como se verá en la sátira siguiente (Ver Figura 4)

El autor reproduce un símbolo generado en el incidente ocurrido en Francia, consciente de que los recuerdos todavía se mantenían en la memoria de sus lectores, para poner de relieve otro atentado de proporciones más grandes, olvidado o simplemente ignorado por los grandes medios de comunicación: el atentado realizado por el 
grupo Al Shabaab, compuesto por islamitas somalíes, contra estudiantes de la Universidad de Garissa, en Kenia, que resultó en un total de 147 muertos3 .

Pasados tres meses del incidente ocurrido en la capital francesa y su enorme conmoción mundial, el masacre en Nairobi, que produjo un número casi trece veces mayor de muertos, recibió una proyección infinitamente menor que el atentado de París.

A través de la historieta, Liniers registra el incidente de forma irónica, cuestionando la ausencia de la conmoción anteriormente direccionada a los franceses. Además, hay un tono acusatorio a la forma en que los medios de comunicación pueden ser parciales de acuerdo con sus intereses. Se invita al lector a reflexionar sobre los dos casos y la respectiva atención dada a cada uno. La tira también se presenta como un registro de una noticia que ha recibido poca atención, pese a su importancia, en respecto a la memoria de un pueblo por el cual no se ha tenido la misma empatía que aquella expresada a los franceses.

Con este gesto Liniers realiza, por medio de su visión crítica, un homenaje a las víctimas del atentado olvidado por la prensa. La acción de Liniers se convierte en un gesto político, como afirma Caparrós al mencionar que "la crónica es una forma de pararse frente a la información y su política del mundo: una manera de decir que el mundo también puede ser otro. La crónica es política" (2012, p. 610).

De esta manera, sumado al ejercicio de rememorar, este cómic se presenta como la reflexión sobre la experiencia vivida: ¿hasta qué punto realmente podemos sentir la dimensión del atentado ocurrido y adónde direccionamos nuestro duelo? Respecto a esto, Alberto Manguel afirma que:

La memoria, en el Occidente, es el vínculo de nuestra experiencia, a lo largo de la línea temporal, con los repositorios del pasado. En términos inuit, la memoria equivale en todo a la experiencia presente: aquello que se recuerda es la realidad en la cual vivimos, física e imaginativamente. No hay "grados" de conocimiento o reconocimiento en el hecho de rememorar. Somos lo que la experiencia previa nos ha enseñado como individuos o como comunidades - pero, para ser más precisos, tendríamos que dispensar el término "previa". La historia que ha sido contada existe solamente como la historia que se cuenta ahora (Manguel, 2008, p. 79 )4 .

En este sentido, la crónica presentada anteriormente en el espacio del arte secuencial, término creado por Eisner (1999), brinda un homenaje a las docenas de víctimas del atentado en cuestión y también invita al lector a rememorar los eventos sucedidos y repensar su noción de experiencia ante el hecho; más importante, provoca empatía con los kenianos víctimas del atentado y sus respectivos familiares. Repensar esos eventos anteriormente olvidados, a través de la historieta-crónica, permite al público no solamente revisitar y dar la debida atención al caso, sino que también evoca el aprendizaje que la experiencia ante el tema nos trae. Aún en las palabras de Manguel,

Por impalpables que sean, nuestros lenguajes nos dan el poder de imponer cierto orden al mundo; es a través de las historias contadas y recontadas que constituimos nuestras identidades. Por fin, es a través de las palabras de la literatura que expresamos lo mejor de nuestro esfuerzo para imaginar la vida en común (Manguel, 2008, solapa)5. 
Volviendo a los eventos políticos locales, hay otro momento en que Liniers utiliza el espacio de la tira para dejar los "rastros" de una crónica, cuyos elementos trataremos (Ver Figura 5).

Por menores que sean los detalles ofrecidos para llegar al evento en cuestión, el segundo cuadro no solamente nos "entrega" dicho evento como fácilmente ubica a los argentinos en el tiempo que ha sido publicada: se tratan de las elecciones presidenciales ocurridas el 22 de noviembre de 2015. En ese momento, y así Liniers lo mimetiza en su tira cómica, los ciudadanos argentinos se dividían entre dos propuestas políticas completamente divergentes a la hora de elegir el sucesor de Cristina Kirchner: de un lado tenían a Mauricio Macri, que presentaba un seductor discurso neoliberal y como una posible solución para los innúmeros problemas que sufría la sociedad argentina, tales como la inseguridad e inflación crecientes; del otro lado podrían elegir a Daniel Scioli, candidato indicado por la presidente, que defendía la continuidad de las políticas sociales Kirchneristas.

El momento fue de grande tensión política y social, dado que la sociedad enfrentaba recurrentes quiebres y crisis económicas tras 12 años de gobiernos Kirchneristas, mientras se temía la amenaza de un gobierno neoliberal y sus posibles fantasmas, como las privatizaciones y cortes de subsidios e inversiones en programas sociales.

Sin posicionarse ante la inminente decisión que habría de tomar la población, Liniers sintetiza en la tira cómica, de manera precisa en cada uno de los cuadros, la inquietud que sufría argentina en ese momento: la cuestión planteada por uno de los personajes en el primer cuadro, evidenciando que el sentimiento de duda era un síntoma general; después, el titubeo del otro personaje, que a través de un efecto cómico, mezcla en el globo los nombres de ambos candidatos en su respuesta; el silencio incómodo del tercer cuadro, tanto de parte de quien escucha como de parte de quien responde; y por fin, la consolidación de la inquietud: la respuesta que ya era insatisfactoria todavía no es cierta.

Liniers representa con tamaña precisión la incomodidad de una situación, tan particular a la sociedad argentina que, no se sabe al cierto la razón, esta tira nunca ha sido copilada en libro, quedándose en la comunidad local, lo que la impide de circular en otros países, a pesar de estar disponible en internet, si estuviese en uno de los libros de la serie. Tal vez por la particularidad o por la fugacidad del tema, no se sabe al cierto; el tema de la circulación puede ser materia para un estudio futuro, desvelando otras características por detrás de la crónicahistorieta.

A modo de conclusión, de manera general los estudios literarios ya no tienen la pretensión de definir qué es literatura en la actualidad: es de conocimiento amplio que las fronteras entre el lenguaje literario y las otras formas de narrar se han acercado bastante, inaugurando nuevas formas de contar historias, por medio de un intercambio entre distintos lenguajes. Las narrativas gráficas, en su forma multifacética y dinámica de expresión, naturalmente incorporan mecanismos originarios de otros géneros, como se ha visto en este estudio con el caso de la crónica. La capacidad se huir de la realidad para representar su universo fantástico no es la única habilidad de Liniers: al mismo tiempo, el autor nos muestra ser posible, sin salir de su territorio discursivo, utilizar el arte secuencial para mimetizar la crónica, ampliando las formas posibles de registrar la identidad política y la historia.

Conviene destacar que la velocidad con la cual el autor se manifiesta -inmediatamente a los eventos sucedidosal menos en las situaciones utilizadas en este estudio, se debe gracias a internet: si los medios de elaborar la 
crónica se transformaron con el paso de los años, es natural que las formas de producción y circulación de estas narrativas también se hayan modificado, conforme decía Ludmer. El soporte de la crónica, anteriormente físico el periódico impreso- adquiere agilidad en el mundo virtual, con el objetivo de acompañar la velocidad con la cual las noticias se propagan en esos ambientes; de ahí surgen las "tiras-crónicas", facilitando al público la asociación de los eventos representados en la narrativa gráfica a la realidad. No solo Liniers, sino otros historietistas consagrados han empezado a utilizar las redes sociales para promocionar sus tiras, que frecuentemente reflexionan sobre acontecimientos puntuales. En Brasil, los historietistas Laerte y André Dahmer reportan con frecuencia temas del cotidiano político, económico y social a través de las redes sociales.

Realizando una lectura atenta de la obra de Liniers, se nota que, a pesar de su tono comúnmente fantástico, es posible observar que hay otra habilidad presente en la obra de este consagrado historietista argentino: el poder de observar críticamente la realidad de su entorno, y, por medio de su sensibilidad y empatía con los hechos, reivindicar un mundo mejor a través de su particular comicidad.

Notas

1. Más información sobre el caso en el siguiente enlace del diario La Nación: . Acceso el 16.04.2016.

2. Más información sobre el caso en el siguiente enlace: . Acceso el 17.04. 2016.

3. Más información sobre el caso en el siguiente enlace: . Acceso en 16.04.2016.

4. Adaptación de la versión en portugués a la cual se ha tenido acceso.

5. Adaptación de la versión en portugués a la cual se ha tenido acceso.

Bibliografía

Cândido, A. (1980). A vida ao rés-do-chão. In F. Coutinho, M. Carvalho, R. Moreira (Ed.), A vida ao rés-do-chão: artes de Bispo do Rosário (pp. 13-22). Rio de Janeiro: 7Letras.

Caparrós, M. (2012). Por la crónica. In D. J. Agudelo (Ed.). Antología de crónica latinoamericana actual (pp. 607612). México D.F.: Alfaguara.

Eisner, W. (1999). Quadrinhos e arte sequencial. São Paulo: Martins Fontes.

Liniers (2009). El Macanudo universal. Buenos Aires: Editorial Común. (2010). Macanudo 8. Buenos Aires: Editorial Común. Acceso en 17.04.2016.

Ludmer, J. (2013). Aqui América Latina. Trad. Rômulo Monte Alto. Belo Horizonte: Editora UFMG.

Manguel, A. (2008). A cidade das palavras: as histórias que contamos para saber quem somos. Trad. Samuel Titan Jr. São Paulo: Companhia das Letras. 
SEÑAS: diccionario para la enseñanza de la lengua española para brasileños (2013). Trad. Claudia Berliner, Eduardo Brandão, Monica Stahel. 4. ed. São Paulo: Editora WMF Martins Fontes.

Steimberg, O. (2013). Leyendo historietas. Buenos Aires: Eterna Cadencia.

Abstract: this analysis presents a specific cut of comic strips by Argentine comics artist Ricardo Siri, known as Liniers, that compose the series Macanudo, published since 2002 in the pages of the newspaper La Nación. Although the series is predominantly based on humoristic situations, this selection is intended to show the existing dialogs between the newspaper strips and the news reported by it, under the critical eye of the author, who has a point of view that is sometimes divergent from the one exposed by the mainstream media. In order to understand the functioning of this narrative form, which links comics, literature, and journalism, four strips by the author are analyzed, dialoguing with theorists of these three specific fields, such as Antônio Cândido (1980), Florencia Levin (2015), Josefina Ludmer (2013), Martín Caparrós (2012), and Oscar Masotta (2010), among others.

Key words: Macanudo - Liniers - comics - literature - journalism - chronicle.

Resumo: esta análise apresenta um recorte específico das tiras do quadrinista argentino Ricardo Siri, conhecido como Liniers, que compõem a série Macanudo, publicada desde 2002 nas páginas do jornal La Nación. Apesar da série se fundamentar em situações predominantemente humorísticas, nesta seleção se pretende mostrar os diálogos existentes entre as tiras de jornal e as notícias nele veiculadas, sob o olhar crítico do autor, que exerce um posicionamento por vezes divergente daquele que figura na grande mídia. Para entender o funcionamento desta forma narrativa, que atrela quadrinhos, literatura e jornalismo, são analisadas quatro tiras do autor, dialogando com teóricos destes três campos específicos, a exemplo de Antônio Cândido (1980), Florencia Levin (2015), Josefina Ludmer (2013), Martín Caparrós (2012) e Oscar Masotta (2010), entre outros.

Palavras chave: Macanudo - Liniers - quadrinhos - literatura - jornalismo - crônica.

[Las traducciones de los abstracts al inglés y portugués fueron supervisadas por el autor de cada artículo]

La crónica-historieta en Macanudo, de Liniers fue publicado de la página 85 a página94 en Cuadernos del Centro de Estudios de Diseño y Comunicación N74 